GA-A15520

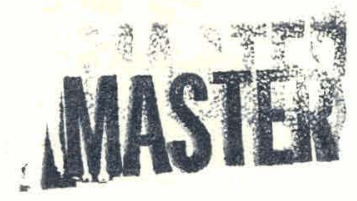

\title{
ASSESSMENT OF A CORE MELTDOWN IN THE GAS-COOLED FAST BREEDER REACTOR WITH AN UPFLOW CORE
}

by

A. TORRI, M. V. FRANK, and C. KANG

\section{GENERAL ATOMIC COMPANY}




\section{DISCLAIMER}

This report was prepared as an account of work sponsored by an agency of the United States Government. Neither the United States Government nor any agency Thereof, nor any of their employees, makes any warranty, express or implied, or assumes any legal liability or responsibility for the accuracy, completeness, or usefulness of any information, apparatus, product, or process disclosed, or represents that its use would not infringe privately owned rights. Reference herein to any specific commercial product, process, or service by trade name, trademark, manufacturer, or otherwise does not necessarily constitute or imply its endorsement, recommendation, or favoring by the United States Government or any agency thereof. The views and opinions of authors expressed herein do not necessarily state or reflect those of the United States Government or any agency thereof. 


\section{DISCLAIMER}

Portions of this document may be illegible in electronic image products. Images are produced from the best available original document. 
This report was prepared as an account of work sponsored by the United States Government. Neither the United States nor the Department of Energy, nor any of their employees, nor any of their contractors, subcontractors, or their employees, makes any warranty, express or implied, or assumes any legal liability or responsibility for the accuracy, completeness or usefulness of any information, apparatus, product or process disclosed, or represents that its use would not infringe privately owned rights. 
GA-A15520

\title{
ASSESSMENT OF A CORE MELTDOWN IN THE GAS-COOLED FAST BREEDER REACTOR WITH AN UPFLOW CORE
}

\author{
by \\ A. TORRI, M. V. FRANK, and C. KANG
}

This is a preprint of a paper presented at the Helium Breeder Associates/Department of Energy GCFR Program Technical Review Meeting, May 31, 1979, Rancho Bernardo, California, and to be published in the Proceedings.

Work supported by

Department of Energy

Contract DE-AT03-76SF71023

GENERAL ATOMIC PROJECT 6112

JULY 1979

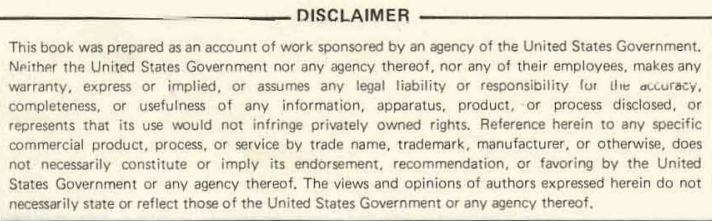


ASSESSMENT OF A CORE MELTDOWN IN THE GAS-COOLED FAST BREEDER REACTOR WITH AN UPFLOW CORE*

\author{
A. Torr1, M. V. Frank, and C. Kang \\ General Atomic Company \\ San Diego, California
}

ABSTRACT

This paper discusses the chronological sequence of events and supporting analysis of a postulated total loss of all coolant circulation in the gascooled fast breeder reactor (GCFR) with an upflow core. Redundant and diverse cooling systems are provided for decay heat removal, including pressurized natural circulation in the core auxiliary cooling system, which reduce the probability of this postulated event below the range of plant design bases. Nevertheless, this postulated accident has been considered so that the potential for consequence mitigation and containment margin could be investigated. Two distinct phases of the sequence are discussed: (1) the core response to a total loss of forced and natural coolant circulation and (2) the capability of the prestressed concrete reactor vessel (PCRV) to retain molten fuel debris. Spectfic design features of the GCFR which prevent recriticality and fuel vaporization due to fuel slumping are under investigation. Analytical work has been initlated to determine the potential for consequence mitigation in the PCRV and the containment. Several concepts for postaccident fuel containment have been Identified and appear technically feasible.

\title{
INTRODUCTION
}

The safety philosophy adopted for the gas-cooled fast breeder reactor. (GCFR) demonstration plant includes two basic elements. First, safety systems are being developed which ensure that the occurrence of a plant condition exceeding the core safety limits is so remote that all accidents leading to loss of coolable core geometry are beyond the plant design basts

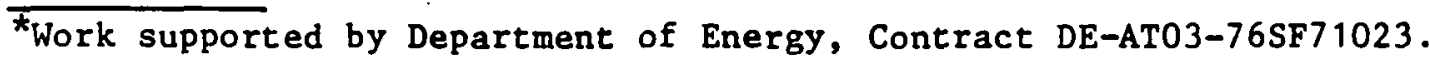


envelope. This objective is being accomplished through a comprehensive design, design analysis, and experiment support program, where the design adequacy is being established according to safety criteria which include safety limits for core temperatures and reliability targets for prevention of core damage. Second, postulated accident sequences which lead to core danage are being investigated in spite of design provisions that remove these sequences from the design basis envelope. The objective is to investigate the consequences of these low probability events to assess if containment margins exist which adequately limit the risk. This is accomplished by mechanistic analyses of the accident progression from event initiation through the core damage phase, the postaccident fuel containment phase, the containment response, and the radiological and environmental consequences. Experimental programs support the development of analytical methods where there are large uncertainties in the physical phenomena involved or in the relative timing of the principal accident phenomena.

This paper discusses the sequence of events inside the PCRV during a postulated total loss of flow in the shut-down GCFR. This accident sequence is referred to as the loss of shutdown cooling (LOSC) accident. Two distinct phases are addressed: (1) core-wide heatup, melting, and relocation of core materials during the initial damage phase and (2) containment of molten fuel and steel on the floor of the central prestressed concrete reactor vessel (PCRV) cavity.

LOSS OF SHUTDŌWN COOLING ACCIDENT PHENOMENA IN AN UPFLOW CORE

In April 1979 the GCFR program changed the GCFR reference design from a top supported downflow core to a bottom supported upflow core to provide the capability for pressurized decay heat removal by natural coolant circulation from the core to the ultimate heat sink.

The hypothetical LOSC accident in the GCFR is initiated by loss of all forced circulation and failure to establish natural circulation in a shutdown reactor. This accident is analyzed to investigate the potential 
for consequence mitigation and containment margin, because its potential for core disruption may be greater than for unprotected accidents (Ref. 1). This accident has been named LOSC to distinguish it from the protected loss of flow (PLOF) accident in a downflow core design. The LOSC is investigated at a variety of system pressures at and below nominal operating pressure, because the consequence potential may increase with decreasing helium pressure in the PCRV.

The postulated initiation of the LOSC accident is of particular concern in a depressurized GCFR. Because of this concern, scheduled depressurization for refueling and maintenance will be under carefully controlled conditions only after a post-shutdown decay time and after establishing the readiness of all redundant decay heat removal systems. These systems are expected to be available for accidental depressurizations if such accidents reduce the pressures below effective natural convection levels. Some conceptual work on this type of accident for a downflow core has been reported (Refs. 2 through 4). Reference 5 discusses analyses of the core-wide progression of the accident sequence and identifies the key phenomena associated with this event. This paper presents the major phenomena of the LOSC accident in an upflow core and then addresses some general considerations for mitigation of the accident consequences.

In the continued absence of all flow, the core would approach complete melting under decay heat at a rate of about 5 to $10 \mathrm{~K} / \mathrm{s}$. Figure 1 shows the core-wide melting sequence at the core axial midplane. For this reference case, it was assumed that reactor scram occurs simultaneously with common loss of drive power to the main circulator motors. The main circulators coast down on their mechanical inertia, and the pony motors on the main circulators are assumed to fail to energize, and the CACS is assumed to fail to start. The GCFK upflow design has the ab1l1ty to provide natural circulation cooling from the core through the CACS loops and to the ultimate heat sink. This must also be postulated to be inoperative to induce a LOSC accident. 
For purposes of analyzing the events following accident initiation, all helium flow through the core is assumed to stop when the Reynolds number decreases to below 2300 (i.e., at $230 \mathrm{~s}$ ). Natural convection effects within the central PCRV cavity have been neglected. Future. analyses will include this effect. Hence, the decay heat produçed in the fuel is lost to the cladding, the duct walls, and the radial blankets. Core heatup after $230 \mathrm{~s}$ leads to initial cladding melting at $370 \mathrm{~s}$, progressing over essentially the entire core prior to duct melting being initiated at $490 \mathrm{~s}$. Duct melting proceeds fairly uniformly throughout the core, except for the duct portions on the outer core periphery adjacent to the radial blanket. Heatup of the cladding and duct walls adjacent to the radial blanket is significantly delayed owing to heat loss to the cooler radial blanket. Fuel melting is initiated at $650 \mathrm{~s}$, with essentially all the cladding and most of the duct walls melted.

Molten steel draining from the core to the lower axial blanket within each assembly is calculated to refreeze within about $50 \mathrm{~mm}$ of the core/ lower blanket interface. The formation of steel blockages in the lower axial blanket (Ref. 4) would provide a platform upon which fuel would accumulate. One postulated mode of fuel compaction is from fuel melting and relocating onto this steel platform. One such representative sequence was analyzed. The combination of material relocation reactivity insertions may overcome the absorber rod worth when about $30 \%$ of the fuel has melted.

Another postulated mude of fuel compaction is declad fuel rod crumbling prior to fuel melting. A radial temperature gradient which induces fuel rod bowing develops in the fuel rods adjacent to the duct wall well before fuel melting. The deflections have been analyzed assuming that the declad fuel rods are fixed at the core/lower axial blanket interface owing to molten steel refreezing. At the interface between the core and the upper axial blanket, it was assumed that the fucl rods brcak frcc and are restrained by only the duct wall or neighboring fuel rods. Bonding between fuel pellets was assumed to occur during normal operation and during heatup to cladding melting. Most evidence from TREAT fuel melting 
experiments on irradiated fuel indicates that even under much more rapid heatup, fuel collapse due to crumbling has not occurred, although fuel rods may break after cladding melting. However, the lack of evidence of fuel crumbling from existing TREAT data cannot be taken as a guarantee that fuel crumbling will not occur during an LOSC event sequence.

Figure 2 shows the fuel rod deflection profiles at the time of duct midflat melting. The stresses calculated from these deflections would cause the first two rods adjacent to the duct wall to fracture near the bottom. Following such a fracture, temporary stress relaxation would occur. The subsequent behavior of the rods is not well understood at this time; however, extensive and core-wide crumbling of fuel before fuel melting is not currently expected. Fuel swelling under these accident conditions may tend to stabilize the declad fuel rods, further reducing the potential for fuel crumbling. In order for recriticality to occur, more than $50 \%$ of the core fuel would be required to crumble into a packing fraction of $60 \%$. In-pile experimental data under LOSC conditions are likely to be required to fully resolve the fuel crumbling recriticality concern during an LOSC sequence.

Containment of fuel vapor released due to fuel melting and slumpinginduced recriticality therefore remains the principal concern during an LOSC sequence in an upflow core. Containment of the energy release is of lesser concern owing to the inefficiency of energy transmission through a gaseous coolant and the large energy absorption capability of the PCRV (Ref. 6).

Experimental information is required to further identify the important LOSC phenomena and improve the analytical evaluation of the event sequence. lhree types of experiments are being considered and are in various stages of implementation. The steel melting and relocation test (SMAR') program at the Los Alamos Scientific Laboratory will provide valuable experimental data on the physical phenomena related to cladding and duct melting; draining, and refreezing and on the effects of helium 
natural convection at $8.6 \mathrm{MPa}$ on the melting sequence. The first test in the heater rod qualification experiment series (FLS-1) has already demonstrated that there is very significant axial heat transport from the core to the upper blanket; as a result, a mechanistic natural circulation model is being developed. The direct electric heating (DEH) facility at Argonne National Laboratury (ANL) will be used to provide data on the strength of fuel pellet honding and the extent of fuel swelling during an LOSC heatup. However, unless the currently planned analytical and experimental programs indicate the possibility of terminating the LOSC accident sequence in the core prior to recriticality, it is expected that in-pile transient tests in the GRIST-2 facility will be required to better quantify the consequences and the fuel dispersal characteristics resulting from fuel slumping or fuel crumbling-induced recriticality.

Future analytical efforts will include incorporation of experimental results and a more mechanistic evaluation of the accident sequence including natural convection, fuel/steel thermal interactions, and fuel relocation modeling.

POSTACCIDENT FUEL CONTAINMENT FOLLOWING A LOSS OF SHUTDOWN COOLING ACCIDENT

The GCFR utilizes a PCRV which contains the core and all primary heat transport equipment. The PCRV is lined with a steel liner which is cooled by cooling tubes attached to the concrete side of the liner, and thermal and radiation shielding is located on the inslde of the lines. The normally cooled liner and shielding present a barrier for the containment of molten fuel in the GCFR. To establish the degree to which this barrier would contain molten fuel, several conceptual design options have been evaluated. The principal constraints are the space limitation imposed by the liner dimension and the absence of a liquid coolant which can absorb the upward-flowing heat from a molten tuel pool.

The analytical methods used for the evaluation of alternate concepts include Baker's empirical model (Ref. 7) for two-dimensional heat transfer in internally heated pouls, conduction heat tranefer through the side and 
bottom structures, and convective and radiative heat transfer from the pool surface to the PCRV internal structures. Postaccident fuel containment concepts for the GCFR have been developed in Germany (Ref. 8), and the U.S. (Refs. 9 through 13). Among these many concepts, the ceramic crucible, the borax bath, the uranium metal bath, and the steel bath have been evaluated and compared for the GCFR.

The ceramic crucible utilizes a buildup of refractory materials, forming a crucible inside the liner to contain the molten core debris with-. out melting or chemical attack of the crucible surface and at the same time to provide the required shielding for normal operation. Previous analyses for a 300-MW(e) GCFR have shown that this concept can be applied to the current GCFR design with some modifications. The thick crucible wall provides a stored heat capaacity that can delay the maximum liner heat flux for $30 \mathrm{~h}$ after core meltdown. The peak heat flux which eventually reaches the cavity liner is sufficiently low so that an enhanced liner cooling capacity would remove the entire downward-flowing heat. However, because of the thick crucible wall, the debris pool temperature exceeds $3000^{\circ} \mathrm{C}$, and the margin for fuel boiling under depressurized conditions is small. In addition, most of the core debris decay heat is driven upward, which makes this concept depend on upward heat removal. The delayed startup of a single core auxiliary cooling system (CACS) loop is sufficient to remove all the upward-flowing decay heat, even at fully depressurized conditions. Furthermore, a residual pressure of $0.6 \mathrm{MPa}$ in the PCRV is sufficient for upward heat removal by natural convection in the CACS loops. Even if no convection, forced or natural, could be established in the CACS loops, the melting of substantial portions of the central cavity internal components would be delayed approximately $24 \mathrm{~h}$. The addition of these internal components to the debris pool represents a substantial incremental heat capacity which would depress pool temperatures for a substantial time period, following which the reduced upward-flowing heat could be removed through the liner insulation to the liner cooling in the upper portion of the central cavity. Therefore, maintaining PCRV liner integrity following a core meltdown appears technically feasible but requires design 
attention for the unique aspects of a core meltdown condition,i.e., liner cooling capability, crucible material flotation, etc.

The BORAX bath concept was proposed for the GCFR by Dalle Donne et al. (Ref. 8). Steel boxes filled with borax $\left(\mathrm{Na}_{2} \mathrm{~B}_{4} \mathrm{O}_{7}\right)$ are installed in the lower reactor cavity. Following a core meltdown, the oxide fuel is expected to dissolve in the liquid borax to form a compound solution pool. The dissolving process is controlled by steel box melting, so that the liquid borax is already at the melting point of steel, where a fast dissolving rate may be achieved. The low boiling point of borax $\left(1700^{\circ} \mathrm{C}\right)$ may cause a borax vapor blanket to form at the fuel-borax interface, so that the fuel and steel may sink through the borax bed without dissolving the fuel. In addition, the borax pool may become separated from the fuel by an intermediate steel layer, interrupting the dissolving process. Small-scale simulation tests performed by Dalle Donne et al. (Ref. 12) indicate that $\mathrm{UO}_{2}$ dissolution can be accomplished in the presence of steel; larger experiments are cuurrently in progress. Only $20 \%$ to $30 \%$ of the decay heat flows upward because of the low pool temperature. Sideward and downward heat fluxes are increased, but the peak heat flux does not occur until about $10 \mathrm{~h}$ (Ref. 11).

The heavy metal bath concept (Refs. 9, 11, 13) utilizes a large mass of high-density, low-melting-point uranium metal alloy installed inside the lower reactor cavity. Following a core meltdown, a low temperature pool of the uranium alloy with solid fuel fragments in suspension is expected to form. The molten pool is contained by the unmelted solid edge of the heavy metal. The principal advantage of this concept is its self-sealing feature. Gaps between structural alloy blocks will become filled by the uranium alloy, which is of higher density than $\mathrm{UO}_{2}$, thereby preventing the penetration of molten $\mathrm{UO}_{2}$ into structural gaps and cracks. Such penetration can locally increase the heat flux to the cavity liner. A heat transfer study (Ref. 13) for a 1500-MW(e) GCFR has shown that removal of heat from the heavy metal bath is feasible with a wide range of suitable pool temperatures. The disadvantages of this concept include 
the high cost of uranium materials, the potential for metal-water reactions if the liner is breached, and the possibility of crusting on top of the heavy metal, which could suspend a significant fraction of the $\mathrm{UO}_{2}$ above the pool. Uranium alloys also have a low heat capacity, requiring a 2-m-thick layer for a $4-h$ heat capacity.

The steel bath concept (Ref. 10) employs a large mass of stainless steel plates that will melt following a core meltdown to form a "light metal bath." This concept is similar to the uranium bath except that the core debris is heavier than the pool material and is collected at the bottom of the steel pool. A refractory layer placed between the steel and the cavity liner is thus needed to protect the liner from potential hot spot effects. Analysis of steel bath heat transfer has shown that the steel core retention system has a greater stored heat effect than the uranium system, and therefore the liner heat flux and temperatures are lower. Similar to the ceramic crucible concept, this concept can be accommodated without a large cost or significant design changes.

Table 1 compares the important parameters for the four concepts. The ceramic crucible is the simplest concept but is most dependent on upward heat removal, whereas the borax bath and the uranium bath offer better performance but would require major design changes and experimental development. The steel bath appears to be an interesting compromise concept, and a combination of the essential features of two concepts, i.e., a heavy metal base with an overlaying steel bath, may offer further improvements. It is concluded that there are several diverse concepts for molten fuel containment inside the PCRV which appear feasible utilizing the normally provided cooled liner barrier for postaccident fuel containment.

All in-vessel molten fuel containment concepts depend on the availability of liner cooling for indefinite retention of molten fuel. The time delay available for restoration of liner cooling depends on the heat capacity provided by the structural material in the lower cavity region and is typically in the range of 4 to $10 \mathrm{~h}$. Since the probability of 
TABLE 1

COMPARISON OF MOLTEN CORE RETENTION CONCEPTS

\begin{tabular}{|c|c|c|c|c|}
\hline Parameter & $\begin{array}{l}\text { Ceramic } \\
\text { Crucible } \\
\end{array}$ & $\begin{array}{l}\text { Borax } \\
\text { Bath } \\
\end{array}$ & $\begin{array}{l}\text { Uranium } \\
\text { Bath } \\
\end{array}$ & $\begin{array}{l}\text { Steel } \\
\text { Bath } \\
\end{array}$ \\
\hline Pool temperature $\left({ }^{\circ} \mathrm{C}\right)$ & $\begin{array}{l}\text { H1gh } \\
(>3000)\end{array}$ & $\begin{array}{l}\text { Low } \\
(1427)\end{array}$ & $\begin{array}{l}\text { Low } \\
(>1200)\end{array}$ & $\begin{array}{l}\text { Low } \\
(>1500)\end{array}$ \\
\hline $\begin{array}{l}\text { Cavity liner tem- } \\
\text { perature }\left({ }^{\circ} \mathrm{C}\right)\end{array}$ & $\begin{array}{l}\text { Low } \\
(150-200)\end{array}$ & $\begin{array}{l}\text { High } \\
(250-300)\end{array}$ & $\begin{array}{l}\text { High } \\
(280-350)\end{array}$ & $\begin{array}{l}\text { High } \\
(250-300)\end{array}$ \\
\hline $\begin{array}{l}\text { Time of maximum liner } \\
\text { heat flux (h) }\end{array}$ & $\begin{array}{l}\text { Long } \\
(28 \div 40)\end{array}$ & $\begin{array}{l}\text { Medium } \\
(\sim 10)\end{array}$ & $\begin{array}{l}\text { Short } \\
(3-4)\end{array}$ & $\begin{array}{l}\text { Medium } \\
(6-10)\end{array}$ \\
\hline $\begin{array}{l}\text { Fraction of upward } \\
\text { heat removal }\end{array}$ & $\begin{array}{l}\text { High } \\
(0.6-0.8)\end{array}$ & $\begin{array}{l}\text { Low } \\
(0.2-0.3)\end{array}$ & $\begin{array}{l}\text { Medium } \\
(0.3-0.4)\end{array}$ & $\begin{array}{l}\text { Low } \\
(0.1-0.3)\end{array}$ \\
\hline $\begin{array}{l}\text { Need for design } \\
\text { changes }\end{array}$ & Minor & Major & Major & Minor \\
\hline $\begin{array}{l}\text { Need for experimental } \\
\text { work }\end{array}$ & Low & High & High & Med Ium \\
\hline Pool manageability & Medium & Low & High & High \\
\hline $\begin{array}{l}\text { Fuel penetration and } \\
\text { material flotation }\end{array}$ & Yes & Yes & No & Yes \\
\hline Scaleability & High & Low & Medium & Medium \\
\hline Cost & Low & Medium & High & Low \\
\hline
\end{tabular}

restoring off-site power in $2 \mathrm{~h}$ is typically $90 \%$, the dependence on liner cooling is not unreasonable. Nevertheless, the consequences of a longer loss of liner cooling was investigated to determine likely PCRV failure modes (Ref. 14). Two speciflc failure modes have been identified and analyzed: (1) failure of PCRV tendons due to sideward growth of the fuel poul pelietrating into the concrete slab and (2) molten fuel penetration through the concrete base mat of the PCRV. Table 2 gives the failure times for these failure modes. Failure of the first row of axial prestressing tendons $31 \mathrm{~h}$ after core meltdown is predicted as the earliest failure mode. This failure mode would only be of importance if the PCRV were still pressurized, a very unlikely condition, because a pressure reduction would be expected through either the PCRV relief valves or the failed liner. In addition, sufficient time for manual depressurization following liner failure is available. Failure by PCRV bottom head penetration requires much longer times, i.e., 11 days for 50\% bottom head penetration and 48 days for full bottom head penetration. 
TABLE 2

COMPARISON OF PCRV FAILURE MODES.

Cause of PCRV Failure

Failure of first row of PCRV tendons

Melt penetration through $50 \%$ of lower PCRV head

Me1t penetration through full PCRV head $\underline{\text { Time of Failure }}^{(a)}$

$31 \mathrm{~h}$

$256 \mathrm{~h}$

48 days

(a) After core meltdown.

It is concluded that very long PCRV failure times can be attained if PCRV depressurization can be accomplished prior to PCRV tendon overheating. Molten fuel penetrating into concrete releases water which can react with an overlaying molten steel pool to form hydrogen. Furthermore, decomposition of limestone aggregate results in the release of $\mathrm{CO}_{2}$. Conservative containment analyses have shown that the containment fallure pressure is not reached for at least $24 \mathrm{~h}$ following liner fallure. Hydrogen evolution is slow and controllable with hydrogen recombination equipment, and containment venting could be delayed beyond $24 \mathrm{~h}$ by use of nonlimestone aggregates in the PCRV bottom head. Therefore, it appears technically possible to contain a molten core inside the PCRV by removing the decay heat through an upgraded liner cooling system and to provide at least 24-h containment integrity even if active heat removal is unavailable.

CONSEQUENCE MITIGATION FOR A LOSS OF SHUTDOWN COOLING ACCIDFNT SEQUENCE

The principal focus of consequence mitigation is the contalnment of condcnacd fuel vapor and fission products released from the core during the postulated meltdown sequence. To quantify the degree of consequence mitigation provided by the PCRV and the containment/confinement structure, radiological consequence analyses are heing performed on the bases of the core releases calculated by ANL: The radiological consequences will provide a basts upon which to judge the adequacy of radiological containment 
provided by the design. In addition, an investigation of the principal means to reduce the radiological consequences further has been inftiated and includes studies on the following:

1. Means to reduce the probability of an LOSC event further.

2. Means to prevent recriticality.

3. Means to minimize fuel vapor and energy release.

4. Means to maintain primary coolant boundary integrity.

5. Means to deplete activity releases to the containment and minimize leakage from the containment/confinement structure.

Completion of these studies, further refinements in accident analysis capabilities, and results of ongoing experimental programs will yield the comprehensive understanding of core disruptive accidents in the upflow core necessary for licensing a demonstration plant.

\section{REFERENCES}

1. Sevy, R., E. E. Morris, and T. Y. C. Wei, "Safety Aspects of the Upflow GCFR," Argonne National Laboratory, presented at the Helium Breeder Assoclates/Department of Energy GCFR Program l'echnical Review Meeting, May 31, 1979.

2. Torri, A., and D. R. Buttemer, "Loss of Flow Accident Phenomenology In the GCFR," Trans. Am. Nucl. Soc. 21, 295 (1975).

3. Torri, A., and J. L. Tomkins, "Accident Termination by Element Dropout in the GCFR," in Proceedings of the Fast Reactor Safety Meeting, Chicago, October 5-8, 1976, pp. 1183-1194 (CONF-761001).

4. Torri, A., M. V. Frank, and C. Kang, "A Core Meltdown Assessment in the Gas-Cooled Fast Reactor," in Proceedings of the International GCFR Safety Specialist Meeting, Brussels, Belgium, March 1979, to be published. 
5. Frank, M. V., and J. T. Reilly, "Event Sequence Quantification for a Loss of Shutdown Cooling Accident in the GCFR," in Proceedings of the International Meeting on Fast Reactor Safety Technology, Seattle, August 1979, to be published.

6. Conner, J. G., Jr., and M. E. Giltrud, "Evaluation of GCFR PCRV Containment Capability," White Oak Laboratory Report NSWL/WOL/TR 77-42, April 1977.

7. Baker, L., et al., "Heat Removal from Molten Fuel Pools," In Proceedings of the International Meeting on Fast Reactor Safety and Related Physics, October 5-8, 1976, Chicago, p. 2056 (CONF-761001).

8. Dalle Donne, M., S. Dorner, and K. Schretzmann, "Post Accident Heat Removal Considerations for Gas-Cooled Fast Breeder Reactors," Paper presented at the NEA Coordinating Group on GCFR Development Specialist Meeting on Design, Safety, and Development of the GCFR, Tokyo, March 1976.

9. "Gas-Cooled Fast Breeder Reactor Quarterly Progress Report for the Period May 1, 1977 Through July 31, 1977," DOE Report GA-A14492, General Atomic Company, August 1977.

10. "Gas-Cooled Fast Breeder Reactor Quarterly Progress Report for the Period November 1, 1977 Through January 31, 1978," DOE Report GA-A14771, General Atomic Company, February 1978.

11. "Gas-Cooled Fast Breeder Reactor Quarterly Progress Report for the Period February 1, 1978 Through April 30, 1978," DOE Report GA-A14928, General. Atomic Company, May 1978.

12. Dalle Donne, M., S. Dorner, and G. Schumacher, "Development Work for a Borax Internal Core-Catcher for a Gas-Cooled Fast Reactor," Nucl. Technol. 39, 138-154 (1978).

13. "Gas-Cooled Fast Breeder Reactor Quarterly Progress Report for the Period May 1, 1978 Through .July 31, 1978," DOE Report GA-A15454, General Atomic Company, August 1978.

14. "Gas-Cooled Fast Breeder Reactor Quarterly Progress Report for the Period November 1, 1978 Through January 31, 1979," DOE Report GA-A15237, General Atomic Company, February 1979. 


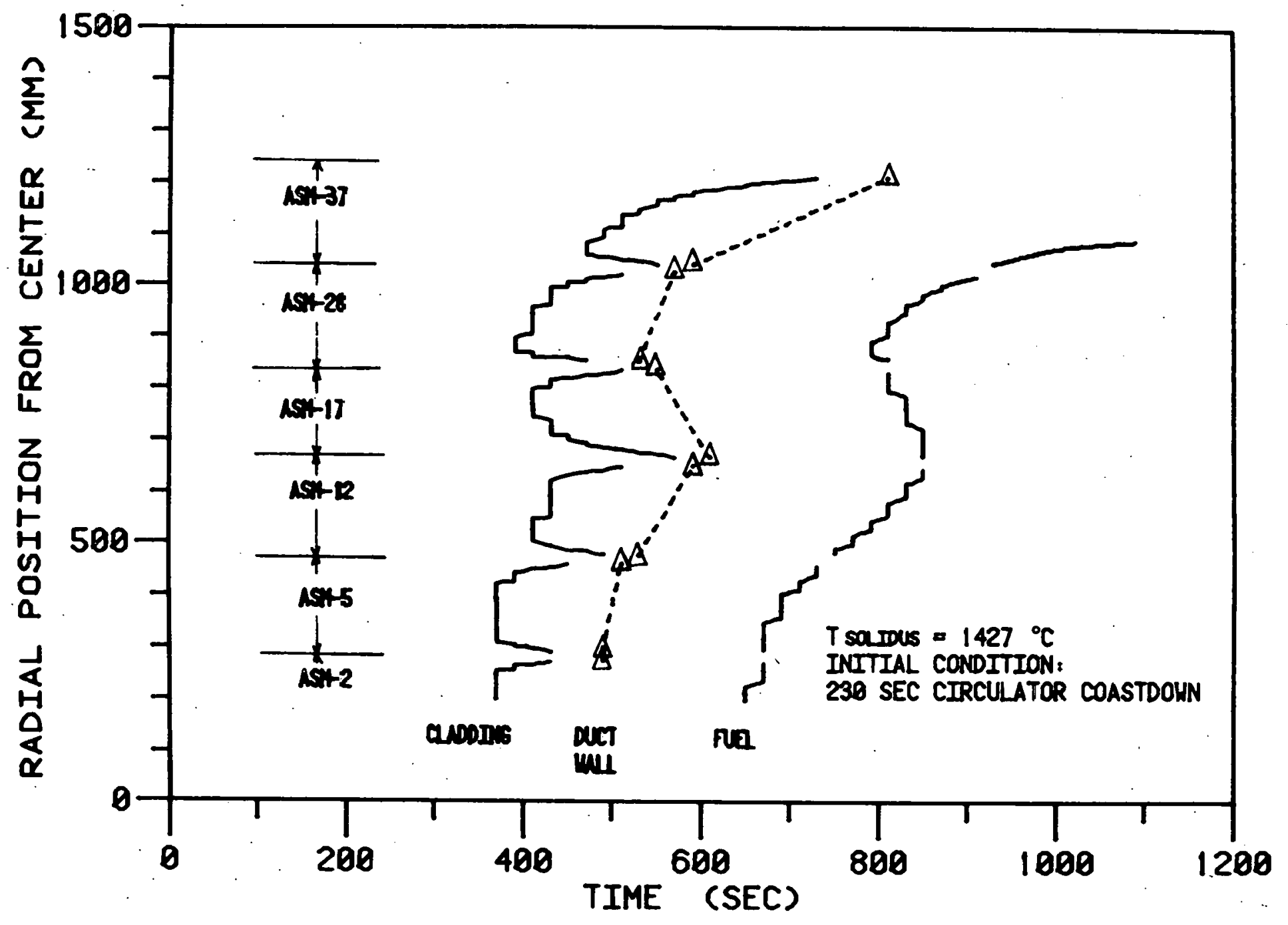

Fig. 1. Material melting sequence for the whole-core case 


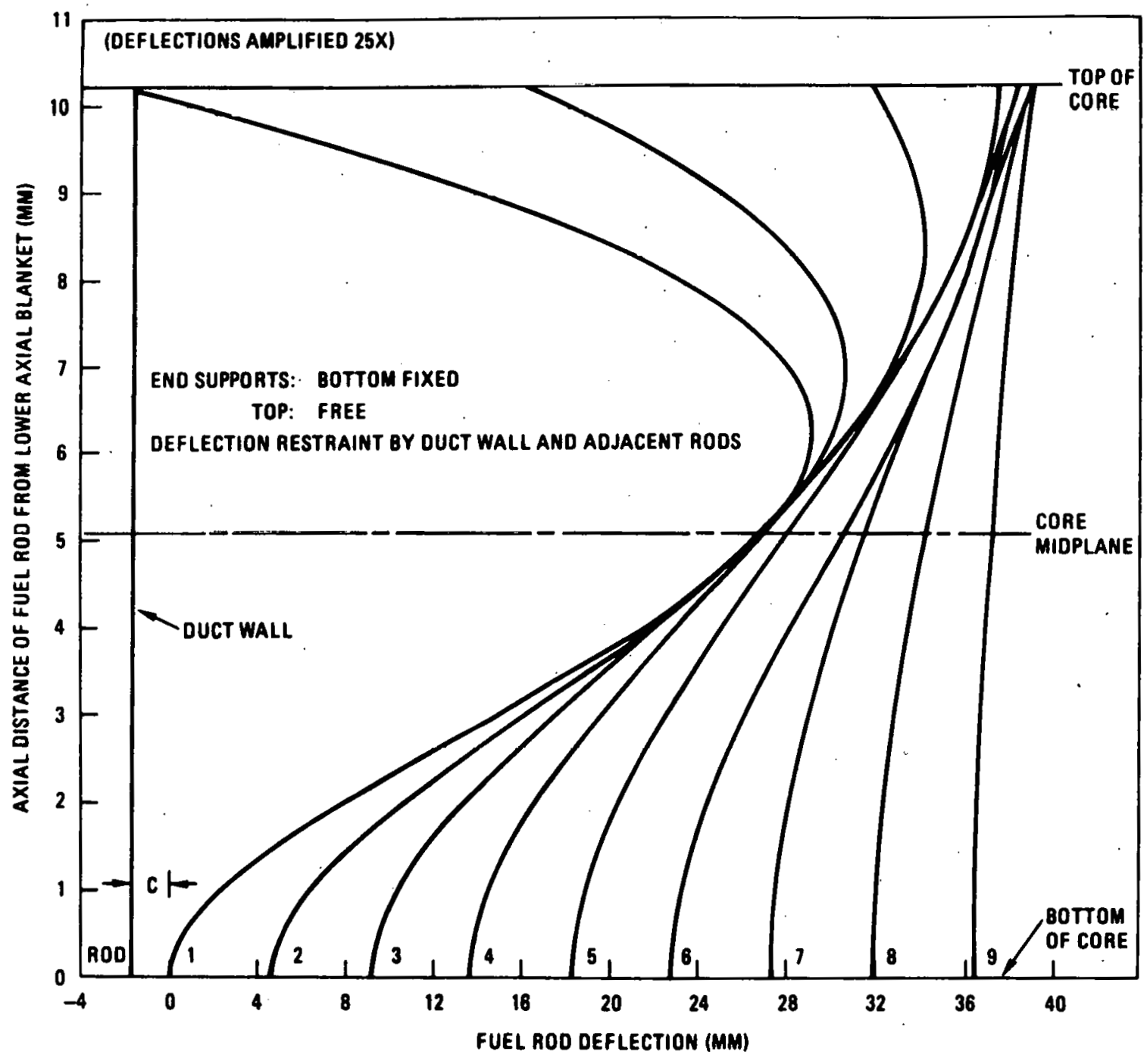

F1g. 2. Thermal deflection of declad fuel rod along a traverse to the midflat at the time of $50 \%$ heat of fusion at the duct midflat 